\title{
A Rational Interpretation of the Role of Turbulence in Particle-Bubble Interactions
}

\author{
Ning Yao ${ }^{1}$, Jingting Liu ${ }^{1}$, Xun Sun ${ }^{1}$, Yan Liu ${ }^{1, *}$, Songying Chen ${ }^{1} \mathbb{D}$ and Guichao Wang ${ }^{1,2, *}$ \\ 1 Key Laboratory of High-Efficiency and Clean Mechanical Manufacture, School of Mechanical Engineering, \\ Shandong University, Jinan 250061, China; 202034395@mail.sdu.edu.cn (N.Y.); liujingting@sdu.edu.cn (J.L.); \\ xunsun@sdu.edu.cn (X.S.); chensy66@sdu.edu.cn (S.C.) \\ 2 SUSTech Academy for Advanced Interdisciplinary Studies, Southern University of Science and Technology, \\ Shenzhen 518055, China \\ * Correspondence: liuyan_2006@sdu.edu.cn (Y.L.); guichao.wang@uon.edu.au (G.W.)
}

Citation: Yao, N.; Liu, J.; Sun, X.; Liu, Y.; Chen, S.; Wang, G. A Rational

Interpretation of the Role of

Turbulence in Particle-Bubble Interactions. Minerals 2021, 11, 1006. https://doi.org/10.3390/min11091006

Academic Editors: Cyril O'Connor,

Pavlína Basařová and

Vladimír Čablík

Received: 17 August 2021

Accepted: 13 September 2021

Published: 15 September 2021

Publisher's Note: MDPI stays neutral with regard to jurisdictional claims in published maps and institutional affiliations.

\begin{abstract}
Interactions between particles and bubbles have been cornerstone for the successful applications of froth flotation to the beneficiations of minerals or coal. Particle-bubble interactions are highly physio-chemical processes on the basis of surface science and hydrodynamics. Though these two aspects are deeply interwoven, we focus on the discussions of the effects of turbulence on the interactions between particles and bubbles, i.e., collision, attachment and detachment. It has to be mentioned this effect is not working in one direction and can affect flotation performance in a complicated way. Only when turbulence effects are well understood, flotation processes can be optimised by suitably changing equipment structure or operating parameters. The aim of this paper is to review the most recent progresses in this aspect and to identify the future development in successfully considering turbulence effects on flotation processes.
\end{abstract}

Keywords: flotation; turbulence effects; bubble-particle collision; attachment; detachment

\section{Introduction}

Froth flotation is an important operation for the recovery of valuable minerals in the mining industry. The essence of flotation processes lies in the interactions between particles and bubbles, which can be categorized into three successive sub-processes which are bubble-particle collision, attachment and detachment [1,2]. These three sub-processes determine the overall performance of flotation processes for treating a particular ore. There are limitations of flotation operation in treating particles of different sizes [3,4]. This size limitation can be varied for different type of ores and flotation works well for particles of base metal ores in the range 20 to $150 \mu \mathrm{m}$ in diameter [5]. Recovery of fine and coarse particles declines progressively and underlying reasons are different depending particle size [6].

Fine particles with small inertia will more likely follow streamline and therefore have lower chance of colliding with a bubble $[7,8]$. Though this is not a problem for coarse particle flotation, coarse particles with higher inertia would more likely detach with modest disturbances from surrounding liquid motion [9]. Therefore, studying interactions between particles and bubbles are fundamental to improve flotation performance. It is unavoidable that fine particles are produced in the grinding processes for the beneficiation of minerals [10]. Moreover, it is desirable to treat coarse particles using flotation for the early rejection of gangue as large amount of energy can be saved in the comminution processes [11]. It is highly necessary for studying particle-bubble interactions under the effects of turbulent flows as they are limiting factors in determining flotation performance [12,13].

Studies have been directed towards expanding size limit $[14,15]$ and manipulating particle-bubble capture [16]. Studying particle-bubble interactions in turbulence is key to expand size limit and improve flotation performance. We have done a systematic endeavor 
to understand the effects of turbulence, especially on particle-bubble collision and particle detachment. Critical literature reviews on separate sub-processes have been presented on particle-bubble collisions [17,18], attachment [19-21] and detachment [22]. It is desirable to combine these three sub-processes together and consider the effects of turbulence on the flotation process as a whole. The effects of turbulence on the particle-bubble interactions in general is considered to be a stochastic process [23]. It can be attributed to the dynamic interactions between particles or bubbles with the turbulent eddies in flotation environment. On one side, hydrodynamics in flotation machines need to be characterized [24], and on the other side, how turbulence control sub-processes in flotation machines should be examined [13]. In this way, hydrodynamics in flotation machines can be optimized to improve flotation performance [24]. Though some classical work in old days have been cited, we aim to collect literature in this century.

This work is intended to explore the effects of turbulence on the particle-bubble interactions. Especially most recent numerical and experimental work from our group will be summarized in regarding to the effects of turbulent on particle-bubble collision and the detachment of particles from the surfaces of bubbles. Emphasis will be directed towards in depth analysis of the turbulence effects on the whole flotation process.

\section{Particle-Bubble Collision, Attachment and Detachment}

\subsection{Effects of Turbulence on Collision}

Due to the limitations of current experimental techniques for studying particle-bubble collisions in turbulent flows, to the best of authors' knowledge, there is no experimental work reported on the collisions between particles and bubbles in turbulent flotation processes. Simplified experiments were designed to study particle-bubble collision efficiency where single bubbles rose in the quiescent slurry $[25,26]$. Single bubble flotation experiments were designed to study. Particles were considered to stay attached to bubbles upon collision and collision efficiency could be represented by particle collection efficiency. Particle-bubble collision was directly observed using a high-speed camera [27-30]. Collisions were represented by direct observations of the falling particles around a positioned bubble. It should be mentioned that these experimental studies did not consider the effects of turbulence on particle-bubble collisions.

Most work on particle-bubble collisions in flotation processes are theoretical analyses or numerical simulations. Various models were developed to calculate particle-bubble collision efficiency and a comprehensive summary can be found in [23,31]. It has to be mentioned that various simplifications and assumptions were made in particle-bubble collision models. Most models assumed particles settled and bubbles rose in a quiescent environment. When a particle encounters a bubble, the particle was considered to follow the streamlines of fluid around the bubble, which was assumed as potential flow or Stokes flow. Most particle-bubble collision models did not account for the effect of turbulent flows. Nevertheless, the effects of turbulence could surpass gravity effects on particle-bubble collisions [32].Nguyen et al. [23] adopted a stochastic modelling approach to consider the effects of turbulence on particle-bubble collision interactions. The stochastic particle-bubble collisions were accounted by correlating motions of particles and bubbles in turbulent flows. They were grouped into either strong correlation or non-correlation. The turbulent collision models by Saffman and Turner [33] and Abrahamson [34] were used to describe turbulent collisions with strong and negligible correlation, respectively. This provides an approach to account for the effects of turbulence on particle-bubble collisions. Nevertheless, mineral particles and bubbles respond to the same turbulent flow in a different way [35]. More discussions should be concentrating on clarifying size effects of turbulent flow structures on particles and bubbles. This is highly dependent on the turbulent characteristics and turbulence intensity in flotation machines. Moreover, the effects of distributions of particles and bubbles on the particle-bubble collisions were not discussed in previous studies.

Most recent studies used computational fluid dynamics (CFD) to study the effect of turbulence on collision efficiency in flotation [36-38]. A single bubble was considered either 
rise at constant velocity or stationary. The Reynolds averaged Navier-Stokes (RANS) model was used to simulate turbulence. Note that this model cannot simulate small turbulent flow structures in the scale of bubbles or particles. To study the effect of turbulence on the collisions between particles, a direct numerical simulation (DNS) model was built in our group $[39,40]$. Collisions between a group of particles and bubbles were studied in a forced homogeneous isotropic turbulence (HIT) as is shown in Figure 1. The turbulence intensity of this background flow was modulated in terms of turbulent energy dissipation rate. Due to most collision models were developed for quiescent liquid, collisions between particles and bubbles in quiescent liquid were simulated and compared to the predictions calculated using widely accept collision models [40]. Results showed collision efficiency as a function of particle diameter and bubble diameter. The collision efficiency between particles and bubbles decreased with increasing bubble diameter and increased with increasing particle diameter, which was in accordance with the general trends of model predictions. In the study of particle-bubble collisions in HIT turbulence, the effects of preferential concentration of particles and bubbles on collision were studied. The collision kernel was found to increase with turbulent dissipation rate as is shown in Figure 2. This was due to the increase of increasing radial relative velocity in more turbulent flows. The effects of preferential concentrations on the particle-bubble collision kernel were ineffective compared to the effects of radial relative velocity.

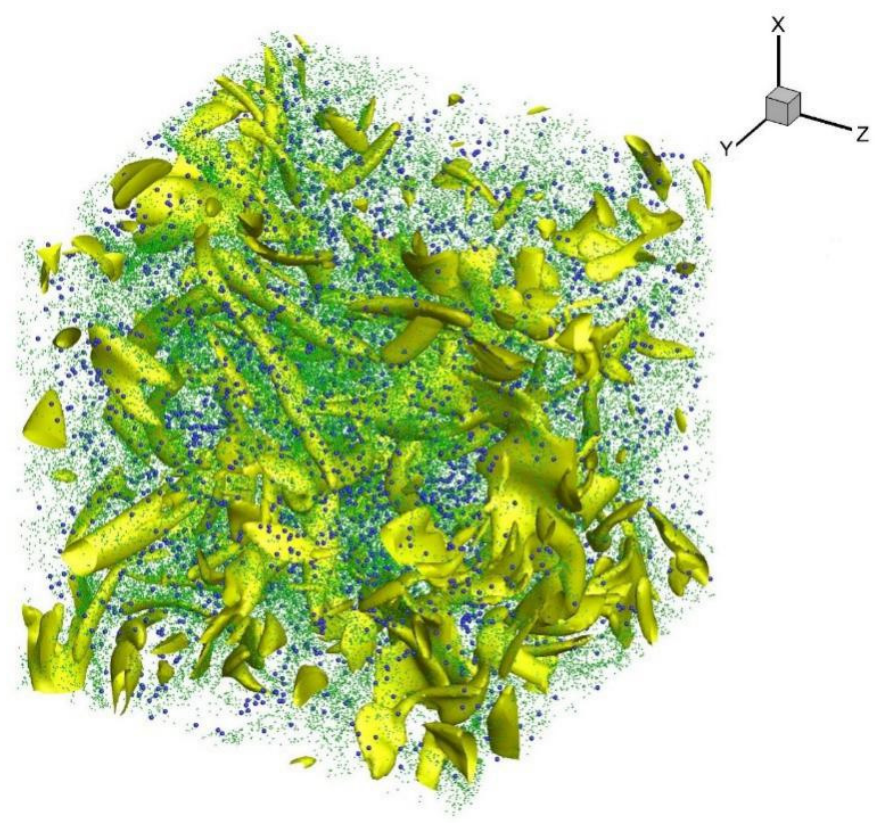

Figure 1. Particles (green dots) and bubbles (blue dots) in a homogeneous isotropic turbulence characterized by 3D vorticity field [40].

Particles and bubbles were considered to be point particles in the above simulations. This will not hold for higher turbulent flows where bubbles and particles will be larger than small turbulent structures. The model was further improved by replacing point-particle model with particle-resolved simulations [41,42]. The dynamic collision kernels and kinematic collision kernels increased with turbulent dissipation rate. This observation was identical to our previous simulations using point-particle method. It has to be mentioned that these simulations considered turbulence as homogeneous and isotropic, whereas in real flotation machines, turbulence can be much more complicated. Direct numerical simulations of real flotation machines have not been achieved yet. Moreover, particleresolved DNS consumes enormous computational cost. Though it can fully represent interactions between turbulent structures and dispersed particles or bubbles, the simulation domain is only dozens of millimetres which is anything but close to real flotation machines. 


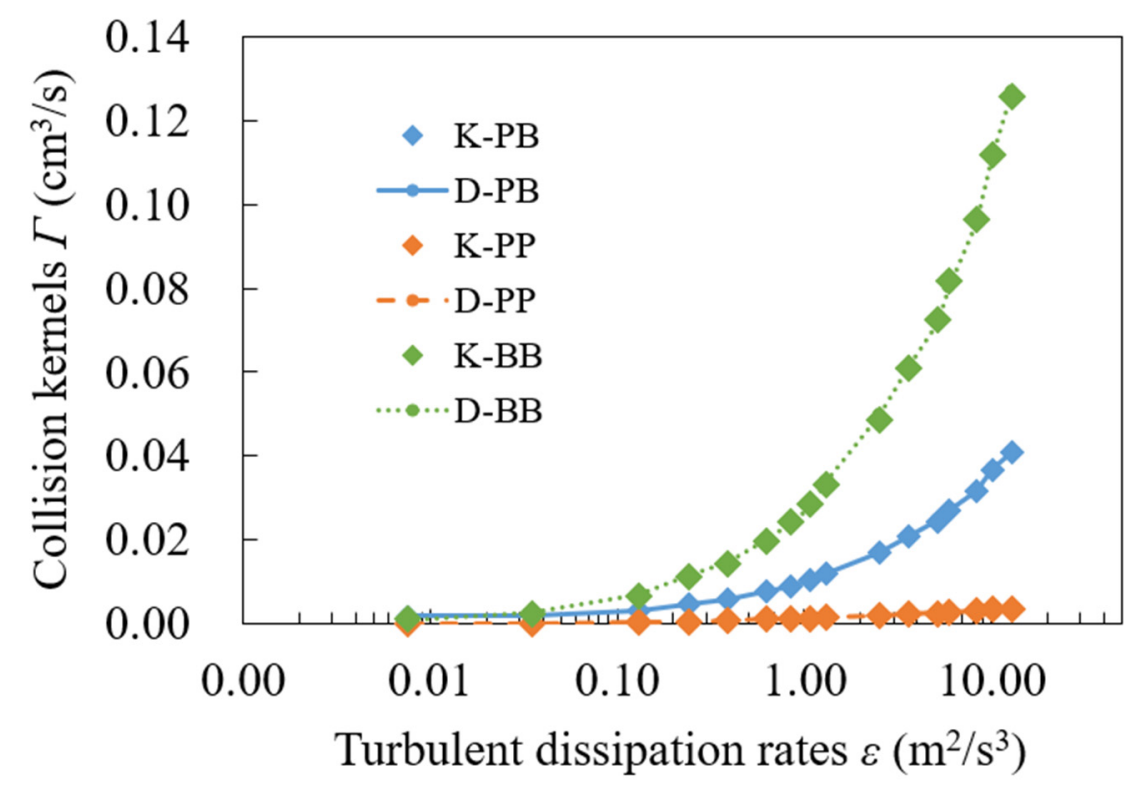

Figure 2. The collision kernels as a function of the turbulent energy dissipation rate [39].

\subsection{Effects of Turbulence on Attachment}

Particle-bubble attachment is characterised by three elementary steps and they are thinning of intervening liquid film to a critical thickness, rupture of critical film and formation of a stable wetting perimeter with the expansion of three-phase contact [20]. Induction time was defined as the time required for above whole process to occur [43], whereas, Albijanic et al. [19] considered induction time as the time of thinning intervening liquid film to a critical thickness. Though there is disagreement on the definition of induction time, it is widely accepted that particle-bubble attachment occurs only when contact time is longer than the induction time. Major parameters affecting particle-bubble attachment are solution chemistry and surfactants, surface chemistry of minerals, and surface forces [44]. The effects of turbulence on attachment process are overlooked or rarely discussed.

The classical Derjaguin-Landau-Verwey-Overbeek (DLVO) theory, combining van der Waals attraction and the electrostatic double layer, has been widely used to describe surface forces between particles. When considering the interaction forces between a particle and a bubble, the hydrophobic force is the major driving force for particle-bubble attachment [45]. The extended DLVO theory (XDLVO) was used to interpret the particle-bubble interactions for the calculation of the flotation probabilities [46]. In flotation processes, high intensity conditioning can be used to treat pulp in improve flotation efficiency [47]. The mechanism of coating removal due to high shear flow has been well studied. It was reported that high intensity conditioning could remove the clay coatings and the oxidation layers on mineral surfaces, promoting the adsorption of the collector [47-49]. The SEM-EDS analysis confirmed that the impact flow could remove the coating covering the coal surface and improve the separation performance of coal from gangue [50]. Intensive turbulence could remove coatings on the particle surface and enhance the adsorption of collector, therefore hydrophobicity and floatability could be substantially improved, which is beneficial to following flotation operations [50]. This could be explained that turbulence is used to increase particle's hydrophobicity, which would enhance thinning of the intervening film in attaching process. Different techniques have been developed to measure the forces and the thin liquid film drainage in the process of particle-bubble attachment [44]. But it has to be mentioned that these measurements rarely consider the effects of turbulence. Only Zhang et al. [51] considered the effects of approaching velocity on the thin liquid film drainage. It was found that the approaching velocity played a significant role in the hydrodynamic pressure and fluid flow within the draining film. In real flotation processes, 
the effects of turbulence on approaching velocity of a particle or a bubble could work in a more complicated way.

The effects of turbulence on particle-bubble attachment could be illustrated from another perspective. Existing studies consider the fluid motionless surrounding an attaching particle-bubble couplet. In real cases, surrounding fluids are highly turbulent and could bring attaching particle-bubble couplet apart by high-frequency fluctuations. This results in shorter contact time, which is insufficient for attachment to occur. Unfortunately, these situations cannot be considered in existing experimental techniques. Thus, future work in this area should aim to combine together the effects of surface chemistry and turbulence.

\subsection{Effects of Turbulence on Detachment}

A comprehensive literature review on the detachment of a particle from the surface of a bubble can be found in [22], where previous studies on the bubble-particle aggregate stability have been critically analysed. The effects of turbulence on the detachment of a particle from the surface of a bubble can be analysed in two perspectives, i.e., force and energy. Schulze $[52,53]$ considered that rotating turbulent eddies interacted with the bubble-particle aggregate in a way that a particle would rotate on the surface of a bubble when the bubble-particle aggregate was trapped in a rotating eddy. The particle would detach when the centrifugal force originated from particle's centrifugal movement is higher than attaching force. Mao and Yoon [54] considered this process from energy perspective and kinetic energy required for detachment to occur was provided by turbulent eddies. There are discrepancies in the sources of turbulent kinetic energy from turbulent structures of different scales [55]. It is noted that exponential distribution function (Table 1) was used in these models to describe particle detachment probability. Researchers seem to accept this without further interrogation and the rationale behind this still remains obscure.

Table 1. Exponential distribution function to describe particle detachment probability.

\begin{tabular}{|c|c|c|c|}
\hline Model & Equation & Model Type & Comments \\
\hline Schulze (1993) [56] & $P_{d}=\exp \left\{1-\frac{6 \sigma \sin ^{2}(\theta / 2)}{d n^{2}\left(\sigma \Delta \rho+\rho p h_{w}\right)-d \rho \sigma \cos ^{2}(\theta / 2)}\right\}$ & Force balance & Particle rotation \\
\hline Hui (2001) [57] & $P_{d}=\exp \left(-\frac{\sigma(1-\cos \theta) d_{B}^{1 / 3}}{14.8 d p^{2} \Delta \rho \varepsilon^{2 / 3}}\right)$ & Force balance & Bubble oscillation \\
\hline $\begin{array}{l}\text { Nguyen and Schulze } \\
\text { (2004) [58] }\end{array}$ & $\begin{array}{l}P_{d}=\exp \left(1-\frac{3 \sigma\left(1-\cos \theta_{A}\right)}{4 R p^{2}\left(g+b_{m}\right) \Delta \rho}\right), \Delta \theta \leq \theta_{R} \\
P_{d}=\exp \left(1-\frac{3 \sigma \sin \theta_{R} \sin (\Delta \theta)}{4 R p^{2}\left(g+b_{m}\right) \Delta \rho}\right), \Delta \theta \geq \theta_{R}\end{array}$ & Force balance & Particle rotation \\
\hline $\begin{array}{l}\text { Nguyen and Schulze } \\
\text { (2004) [58] }\end{array}$ & $\begin{array}{l}P_{d}=\exp \left(1-\frac{3 \sigma\left(1-\cos \theta_{A}\right) \sin (\Delta \theta / 2)}{0.26 \pi \rho_{l} R p \sqrt{\varepsilon v}}\right), \Delta \theta \leq \theta_{R} \\
P_{d}=\exp \left(1-\frac{\sigma \sin \theta_{R} \sin (\Delta \theta) \sin (\Delta \theta / 2)}{0.13 \pi \rho_{l} R p \sqrt{\varepsilon v}}\right), \Delta \theta \geq \theta_{R}\end{array}$ & Force balance & Shear force \\
\hline $\begin{array}{l}\text { Goel and Jameson } \\
\text { (2012) [9] }\end{array}$ & $P_{d}=\exp \left(1-\frac{6 \sigma \sin ^{2}(\theta / 2)}{3.75 d p^{2} \rho p \varepsilon^{2 / 3} / d_{B} 1 / 3}\right)$ & Force balance & Particle rotation \\
\hline Jameson et al. (2007) [59] & $\begin{array}{c}P_{d}=\exp \left(1-\frac{2.34 \sigma^{6 / 5}(1-\cos \theta)}{d p^{2} \Delta \rho \varepsilon^{4 / 5} \rho_{l}^{1 / 5}}\right), \Delta \theta \leq \theta_{R} \\
P_{d}=\exp \left(1-\frac{1.17 \sigma^{6 / 5} \sin \theta_{R} \sin (\Delta \theta)}{d p^{2} \Delta \rho \varepsilon^{4 / 5} \rho_{l}^{1 / 5}}\right), \Delta \theta \geq \theta_{R}\end{array}$ & $\begin{array}{l}\text { Empirical } \\
\text { formula }\end{array}$ & $\begin{array}{l}\text { Energy dissipation rate } \\
\text { is required }\end{array}$ \\
\hline Yoon and Mao (1996) [60] & $P_{d}=\exp \left(-\frac{\sigma \pi R p^{2}(1-\cos \theta)^{2}+\mathrm{E}_{1}}{\frac{\rho g R^{2} \theta_{0}}{3} \pi R p^{2} \sin ^{2} \theta}\right)$ & Energy supply & Steady case \\
\hline Sherrell (2004) [61] & $P_{d}=\exp \left(-\frac{\sigma \pi R p^{2}(1-\cos \theta)^{2}}{\frac{1}{2}\left(m_{p}+m_{b}\right)\left(R_{i m p} \omega\right)^{2}}\right)$ & Energy supply & Limited to stirred tank \\
\hline $\begin{array}{l}\text { Nguyen and Schulze } \\
\text { (2004) [58] }\end{array}$ & $\begin{array}{c}P_{d}=\exp \left(1-\frac{3 \sigma(1-\cos \theta)^{2} \times C}{2 R_{P} \Delta \rho(\Delta V)^{2}}\right) \\
C=\frac{1}{4} \ln \frac{2 L / R_{P} / \sin (\theta / 2)}{e^{\gamma} \cos ^{2}(\theta / 4)}+\frac{13+16 \cos (\theta / 2)+7 \cos \theta}{64 \cos ^{4}(\theta / 4)}\end{array}$ & Energy supply & General shear flow \\
\hline Do (2010) [62] & $P_{d}=\exp \left(-\frac{\sigma \pi R p^{2}(1-\cos \theta)^{2}}{\frac{1}{2} m_{p}\left(\left(d_{p}+d_{b}\right) \sqrt{\varepsilon / v}\right)^{2}}\right)$ & Energy supply & General shear flow \\
\hline Wang (2014) [55] & $P_{d}=\exp \left(-\frac{8 \sigma \pi R p^{2}(1-\cos \theta)^{2}}{c \rho_{l} \varepsilon^{2 / 3} d_{p} 11 / 3}\right)$ & Energy supply & Isotropic turbulence \\
\hline
\end{tabular}

These models are hypothetical in accounting the effects of turbulence on the particle detachment. To unveil the turbulence effects, we developed a series of experiments to 
characterize turbulence and capture detachment process simultaneously. As the movement of a particle-bubble aggregate is random and chaotic in turbulence, it is difficult to capture a freely detaching process using a high-speed camera. We simplified this problem by positioning a solid object and used PIV to characterize turbulence bubble detachment from a cylinder [63] and a sphere [64], as is shown in Figure 3. The flow was very unsteady around the bubble-particle aggregate and discrete wavelet transform (DWT) was used to analyse the contributions of turbulent structures of different scales. The detachment appeared to be a dynamic process. On one hand, instantaneous turbulent velocity field changed dynamically around the detaching couplet. On the other hand, the property of a particle-bubble aggregate changed in the turbulent field. This was characterised by the length of three phase contact [65] and changing dynamic contact angle [66]. The endeavour to find a critical flow information seemed to be in vain as history effect could come into play in the detaching process. It is considered that a particle-bubble couplet experiences disturbances from surrounding turbulent fluid, causing a retraction of three phase contact line. This means less attaching force in stabilization the couplet. The particle can detach from the bubble surface with minor contributions from an instantaneous velocity field which turns into the straw that broke the camel's back.
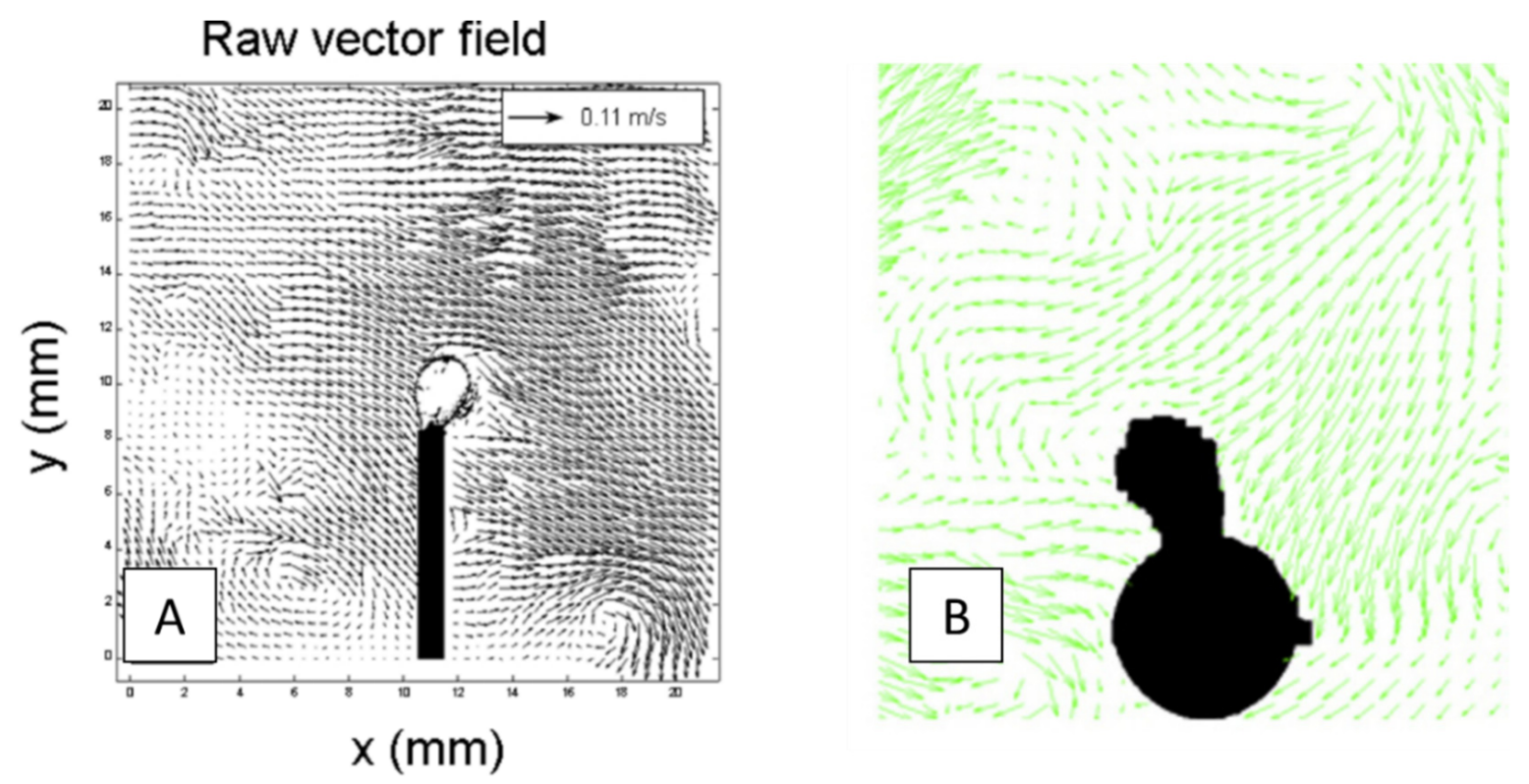

Figure 3. Instantaneous velocity field around a detaching bubble from (A) a cylinder [63] and (B) a sphere [64].

To view the detachment of a freely moving particle-bubble aggregate in a turbulent flow, an experimental apparatus as depicted schematically in Figure 4 was designed, where the movement of aggregates were confined in a wall cavity. Large eddy simulation (LES) was used to simulate turbulent flow fields and turbulence was shown inhomogeneous inside the cavity [67]. For the first time, the hypothesis of particle's centrifugal movement proposed by Schulze [68] was experimentally observed. By tracking the movement of a particle, the rotational speed could reach as high as 200 cycles per second in the rotating vortex, as is shown in Figure 5. A number of different detachment mechanisms were identified, including inertial detachment due to the rapid changes in bubble movement, or because of the oscillations of the bubble's surface [35]. When a bubble was loaded with more than one particle, behaviour of attached particles could become more complicated [35]. It seems impossible to model precisely the series of events that take place in the detachment process, as the particle-bubble detachment in the turbulent field is a stochastic process. 


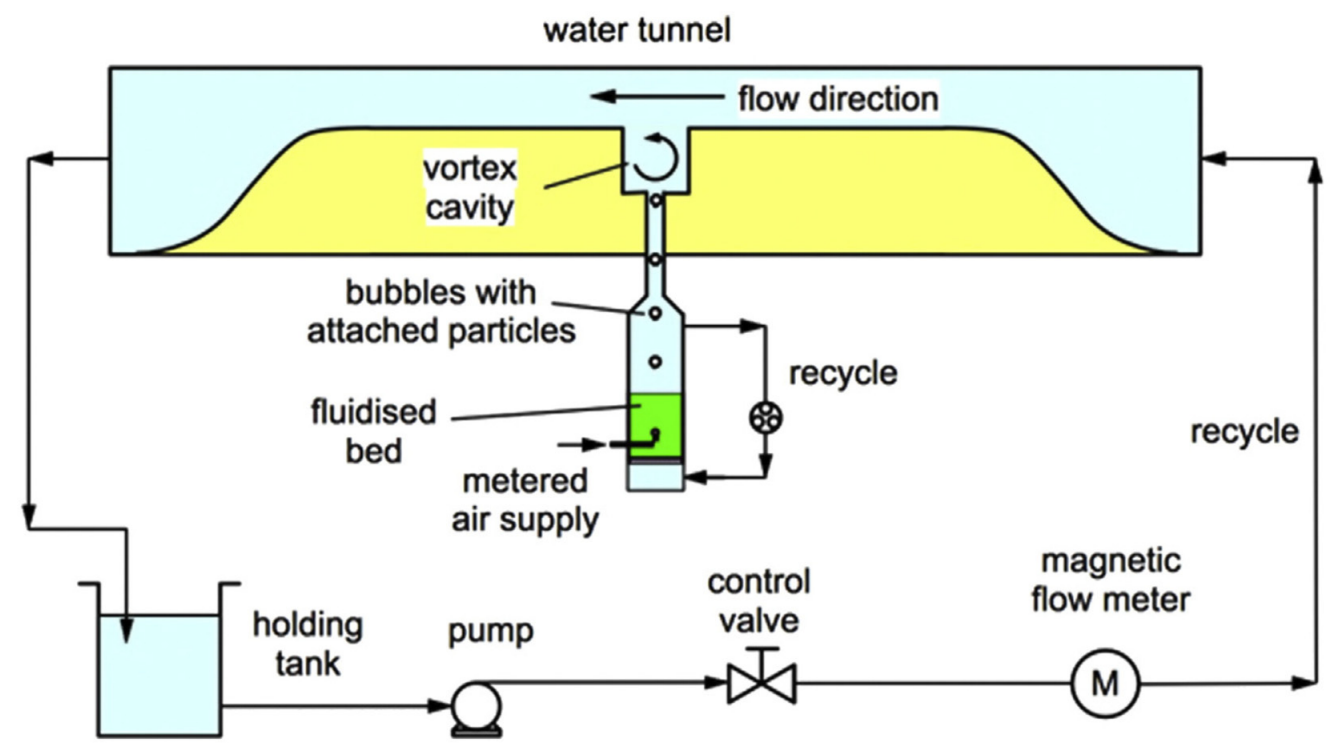

Figure 4. Diagrammatic sketch of the vortex generation apparatus [69].
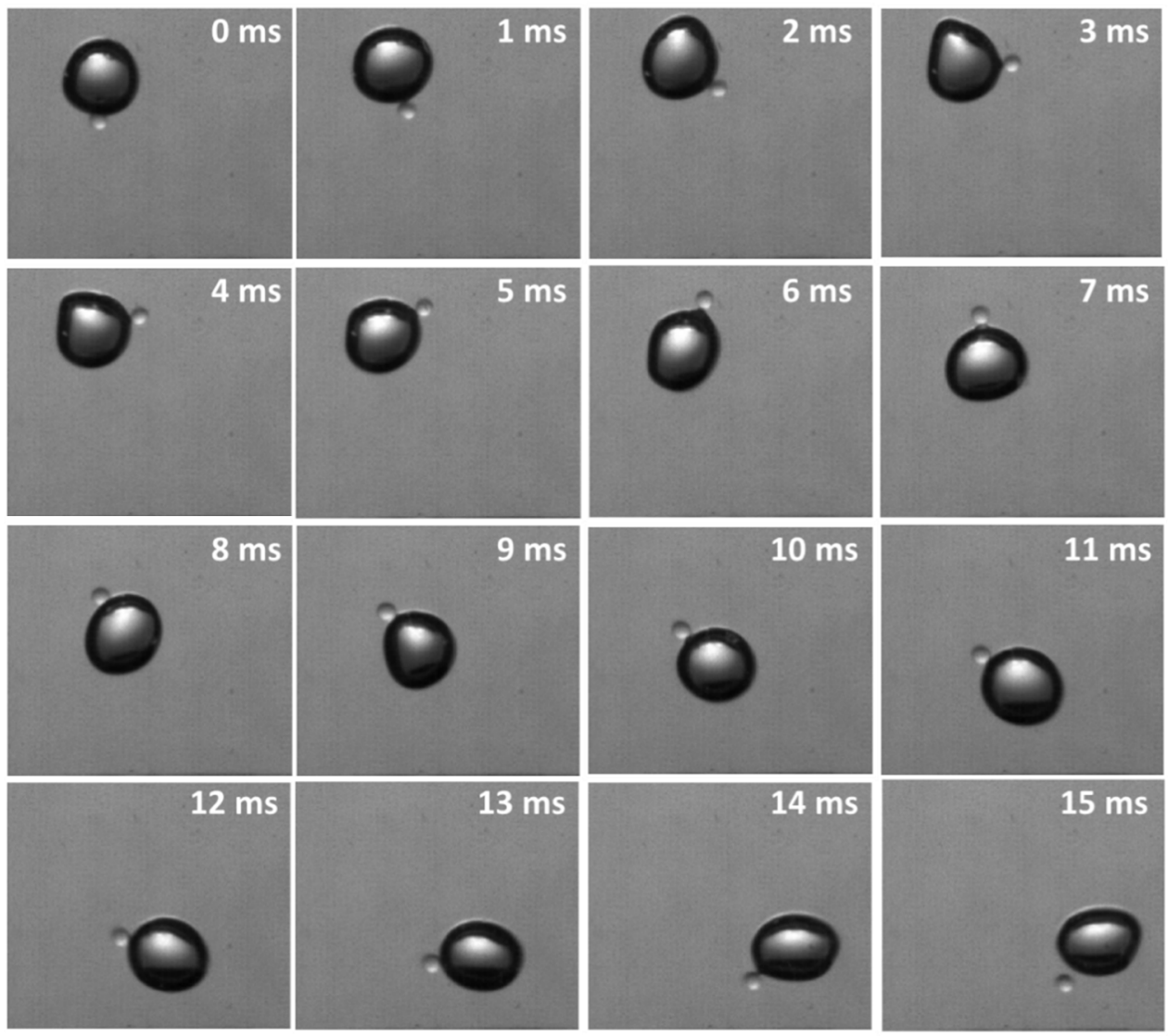

Figure 5. Time series of centrifugal movement of a particle on a bubble surface leading to detachment [70].

\section{Discussions and Recommendations for Further Work}

Though studies of turbulence affecting particle-attachment have been lacking, the roles of turbulence on particle-bubble collision and detachment have been widely accepted. Increasing turbulence intensity is beneficial to particle-bubble collision and causing attached particles to detach from bubbles. This counter acting effect means different approaches in modulating hydrodynamics for fine and coarse particles. For fine particles, different 
methods, such as shockwave by passing a mixture of pulp and air through a chock at high speed [71] and vortex generator [72,73], were used to strengthen turbulence for the flotation of fine particles. When floating coarse particles, a fluidized bed flotation cell was used to generate a relatively gentle flow environment [5,71]. In traditional flotation machines, packing medium was installed in the upper part of a flotation column to increase flotation performance [74-76]. By changing the internal configurations, the flotation column was separated into two parts, where the lower part is turbulent intensive which is beneficial to particle-bubble collision and the upper part has mild flow condition which is favourable to stabilizing attached particles. With good understandings of the effects of turbulence on particle-bubble interactions, flotation processes could be designed based on the energy distribution [77]. By optimizing cell hydrodynamics, flotation efficiency could be improved [78], and the interactions between liquid-solid, gas-liquid and gas-solid could be intensified [12].

Turbulence is an important parameter in flotation, not only by changing interactions between particles and bubbles, but also it has many other functions. Turbulence can affect the adsorption of surfactants, determine bubble breakage and coalescence, bubble size distribution and suspend particles. The effects of turbulence on flotation is generally represented by turbulent dissipation rate. Measuring turbulence in a bubble-particleliquid three phase flotation system represents the utmost challenge for quantifying the effects of turbulence on flotation [79]. Moreover, the accuracy of turbulent dissipation rate is largely determined by measurements resolution $[80,81]$. These factors lead to difficulties in measuring turbulence around interacting particles and bubbles. Without accurate measurements of turbulence in flotation processes, the effects of turbulence on particle-bubble interactions cannot be explicitly determined. Researchers have studied the effects of turbulence on flotation performance as a whole by modulating energy input into the flotation cell [82-85]. Considering the difficulties of measuring turbulence in a three-phase flow system, CFD modelling have been served as a versatile method for studying the effects of turbulence on flotation processes [86]. It should be mentioned that most CFD studies considered the effects of turbulence on particle-bubble interactions by incorporating existing collision, attachment and detachment models. Whereas, these models do not fully represent the effects of turbulence on particle-bubble interactions. This dilemma could be solved if interactions between particles, bubbles and turbulent flows could be directly simulated. However, computational cost would be unaffordable and current CFD simulations could provide valuable information on modifications of internal configurations. As is shown in Figure 6, net attachment rates could be plotted across a stirred flotation cell [87]. This was calculated by assuming single particle size with turbulence information obtained from CFD simulations.

The developments of models of flotation kinetics (particle-bubble collision, attachment and detachment), could improve understandings of flotation processes. When combined with CFD simulations, flotation rate constant and recovery of particles could be predicted. Attention should be paid to the explanation of results, as models of flotation kinetics could not fully reflect the effects of turbulence, and simulated turbulent fields are not truly three phase turbulent flows in flotation machines. Moreover, these models do not consider the effects of particle shape, size and surface compositions, etc. Meanwhile, interactions between particles and bubbles are stochastic in nature in flotation processes with turbulent flows. It follows that there can be no simple model to consider the effects of turbulence on interactions between particles and bubbles. These factors altogether make the simulation of flotation of a real mineral intractable. Machine learning was used to with automated mineralogy data to predict single-particle flotation kinetics $[88,89]$. This is a versatile tool for the optimization of flotation processes. This does not mean that researches of flotation kinetics could be overlooked, which could provide deeper understanding on the physics of particle-bubble collision, attachment and detachment. With these techniques working together, mineral resources could be beneficiated in a more efficient and effective way. 


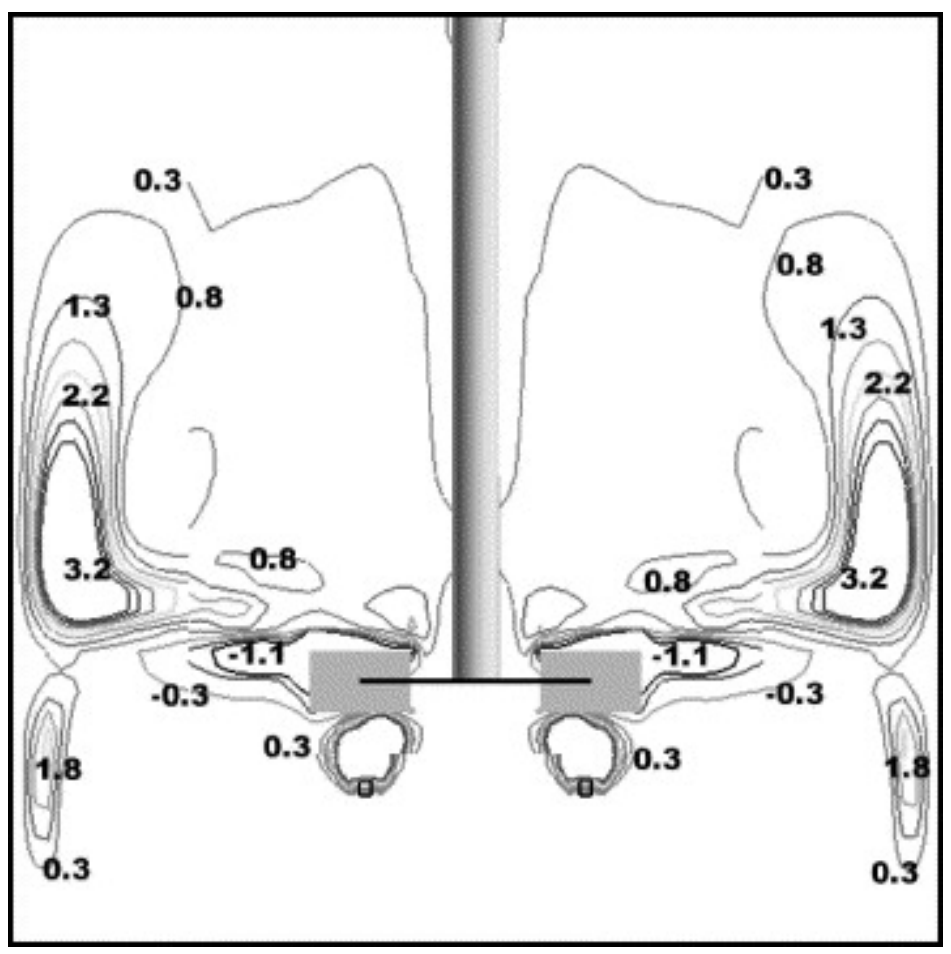

Figure 6. CFD predicted net attachment rates $\left(108 \mathrm{~m}^{-3} \mathrm{~s}^{-1}\right)$ after flotation time of $320 \mathrm{~s}$ for particles of $60 \mu \mathrm{m}$ diameter in the stirred cell [87].

\section{Conclusions}

This work has reviewed most recent progress in the study of particle-bubble interactions in turbulent flows. The effects of turbulence on particle-bubble collision and detachment have been widely studied. On the contrary, the effects of turbulence on particlebubble attachment have been overlooked and is not clearly understood at this stage. This is due to the limitations of existing experimental techniques in measuring attachment process and surrounding liquid flows simultaneously. Increasing turbulence is beneficial to particle-bubble collision, but detrimental to stabilizing particle-bubble aggregates. Modulating hydrodynamics in flotation machines is dependent on the particle size, where turbulence is favoured for the flotation of fine particle and depressed for the flotation of coarse particles. Turbulence inside flotation machines should be optimized to improve flotation performance by maximizing particle-bubble collision and attachment and minimizing particle detachment concurrently. Interactions between particles and bubbles in turbulent flows are stochastic in nature and statistical models with empirical factors can be used to represent the effects of turbulence on flotation.

Funding: This research was supported by the Natural Science Foundation of China under grant numbers 22008141, and by Young Scholars Program of Shandong University, "YSPSDU 31360088964058".

Conflicts of Interest: The authors declare no conflict of interest.

\section{References}

1. Arbiter, N. Flotation rates and flotation efficiency. Trans. AIME. Sept 1951, 791, 796.

2. Jameson, G.; Nam, S.; Young, M.M. Physical factors affecting recovery rates in flotation. Miner. Sci. Eng. 1977, 9, $103-118$.

3. Gaudin, A.M.; Groh, J.O.; Henderson, H.B. Effect of particle size in flotation. Am. Inst. Min. Eng. Tech. Publ. 1931, 414, 3-23.

4. Trahar, W.J. A rational interpretation of the role of particle size in flotation. Int. J. Miner. Process. 1981, 8, 289-327. [CrossRef]

5. Jameson, G.J. Advances in fine and coarse particle flotation. Can. Metall. Q. 2010, 49, 325-330. [CrossRef]

6. Miettinen, T.; Ralston, J.; Fornasiero, D. The limits of fine particle flotation. Miner. Eng. 2010, 23, 420-437. [CrossRef]

7. Jameson, G.; Nguyen, A.; Ata, S. Froth Flotation: A Century of Innovation; Fuerstenau, M.C., Jameson, G.J., Yoon, R.-H., Eds.; SME: Denver, CO, USA, 2007; pp. 329-351. 
8. Ralston, J.; Dukhin, S. The interaction between particles and bubbles. Colloids Surf. A Physicochem. Eng. Asp. 1999, 151, 3-14. [CrossRef]

9. Goel, S.; Jameson, G.J. Detachment of particles from bubbles in an agitated vessel. Miner. Eng. 2012, 36-38, 324-330. [CrossRef]

10. Wang, G.; Bai, X.; Wu, C.; Li, W.; Liu, K.; Kiani, A. Recent advances in the beneficiation of ultrafine coal particles. Fuel Process. Technol. 2018, 178, 104-125. [CrossRef]

11. Franks, G.V.; Forbes, E.; Oshitani, J.; Batterham, R.J. Economic, water and energy evaluation of early rejection of gangue from copper ores using a dry sand fluidised bed separator. Int. J. Miner. Process. 2015, 137, 43-51. [CrossRef]

12. Li, D.; Wang, H.; Yang, L.; Yan, X.; Wang, L.; Zhang, H. Intensification effects of stirred fluid on liquid-solid, gas-liquid and gas-solid interactions in flotation: A review. Chem. Eng. Process. Process Intensif. 2020, 152, 107943. [CrossRef]

13. Schubert, H. On the turbulence-controlled microprocesses in flotation machines. Int. J. Miner. Process. 1999, 56, 257-276. [CrossRef]

14. Kowalczuk, P.B.; Sahbaz, O.; Drzymala, J. Maximum size of floating particles in different flotation cells. Miner. Eng. 2011, 24, 766-771. [CrossRef]

15. Sahbaz, O.; Ercetin, U.; Oteyaka, B. Determination of turbulence and upper size limit in jameson flotation cell by the use of computational fluid dynamic modelling. Physicochem. Probl. Miner. Process. 2012, 48, 533-544.

16. Ralston, J. Controlled flotation processes: Prediction and manipulation of bubble-particle capture. J. South. Afr. Inst. Min. Metall. 1999, 99, 27-34.

17. Dai, Z.; Fornasiero, D.; Ralston, J. Particle-bubble collision models-A review. Adv. Colloid Interface Sci. 2000, 85, 231-256. [CrossRef]

18. Nguyen-Van, A. The collision between fine particles and single air bubbles in flotation. J. Colloid Interface Sci. 1994, 162, 123-128. [CrossRef]

19. Albijanic, B.; Ozdemir, O.; Nguyen, A.V.; Bradshaw, D. A review of induction and attachment times of wetting thin films between air bubbles and particles and its relevance in the separation of particles by flotation. Adv. Colloid Interface Sci. 2010, $159,1-21$. [CrossRef]

20. Nguyen, A.V.; Ralston, J.; Schulze, H.J. On modelling of bubble-particle attachment probability in flotation. Int. J. Miner. Process. 1998, 53, 225-249. [CrossRef]

21. Nguyen, A.V.; Schulze, H.J.; Ralston, J. Elementary steps in particle—Bubble attachment. Int. J. Miner. Process. 1997, 51, 183-195. [CrossRef]

22. Wang, G.; Nguyen, A.V.; Mitra, S.; Joshi, J.B.; Jameson, G.J.; Evans, G.M. A review of the mechanisms and models of bubble-particle detachment in froth flotation. Sep. Purif. Technol. 2016, 170, 155-172. [CrossRef]

23. Nguyen, A.V.; An-Vo, D.-A.; Tran-Cong, T.; Evans, G.M. A review of stochastic description of the turbulence effect on bubbleparticle interactions in flotation. Int. J. Miner. Process. 2016, 156, 75-86. [CrossRef]

24. Schubert, H. On the optimization of hydrodynamics in fine particle flotation. Miner. Eng. 2008, 21, 930-936. [CrossRef]

25. Dai, Z.; Dukhin, S.; Fornasiero, D.; Ralston, J. The inertial hydrodynamic interaction of particles and rising bubbles with mobile surfaces. J. Colloid Interface Sci. 1998, 197, 275-292. [CrossRef] [PubMed]

26. Nutt, C.; Kemp, M.; Weston, J. Rate of Flotation in a Hallimond Tube. Nature 1963, 197, 40-42. [CrossRef]

27. Brabcová, Z.; Karapantsios, T.; Kostoglou, M.; Basařová, P.; Matis, K. Bubble-particle collision interaction in flotation systems. Colloids Surf. A Physicochem. Eng. Asp. 2015, 473, 95-103. [CrossRef]

28. Li, S.; Schwarz, M.P.; Yang, W.; Feng, Y.; Witt, P.; Sun, C. Experimental observations of bubble-particle collisional interaction relevant to froth flotation, and calculation of the associated forces. Miner. Eng. 2020, 151, 106335. [CrossRef]

29. Verrelli, D.I.; Bruckard, W.J.; Koh, P.T.L.; Schwarz, M.P.; Follink, B. Particle shape effects in flotation. Part 1: Microscale experimental observations. Miner. Eng. 2014, 58, 80-89. [CrossRef]

30. Verrelli, D.I.; Koh, P.T.L.; Nguyen, A.V. Particle-bubble interaction and attachment in flotation. Chem. Eng. Sci. 2011, 66, 5910-5921. [CrossRef]

31. Kostoglou, M.; Karapantsios, T.D.; Oikonomidou, O. A critical review on turbulent collision frequency/efficiency models in flotation: Unravelling the path from general coagulation to flotation. Adv. Colloid Interface Sci. 2020, 279, 102158. [CrossRef]

32. Ngo-Cong, D.; Nguyen, A.V.; Tran-Cong, T. Isotropic turbulence surpasses gravity in affecting bubble-particle collision interaction in flotation. Miner. Eng. 2018, 122, 165-175. [CrossRef]

33. Saffman, P.; Turner, J. On the collision of drops in turbulent clouds. J. Fluid Mech. 1956, 1, 16-30. [CrossRef]

34. Abrahamson, J. Collision rates of small particles in a vigorously turbulent fluid. Chem. Eng. Sci. 1975, 30, 1371-1379. [CrossRef]

35. Wang, G.; Evans, G.M.; Jameson, G.J. Bubble movement in a rotating eddy: The implications for particle-bubble detachment. Chem. Eng. Sci. 2017, 161 (Suppl. C), 329-340. [CrossRef]

36. Islam, M.T.; Nguyen, A.V. Effect of microturbulence on bubble-particle collision during the bubble rise in a flotation cell. Miner. Eng. 2020, 155, 106418. [CrossRef]

37. Li, S.; Schwarz, M.P.; Feng, Y.; Witt, P.; Sun, C. A CFD study of particle-bubble collision efficiency in froth flotation. Miner. Eng. 2019, 141, 105855. [CrossRef]

38. Li, S.; Schwarz, M.P.; Feng, Y.; Witt, P.; Sun, C. Numerical investigations into the effect of turbulence on collision efficiency in flotation. Miner. Eng. 2021, 163, 106744. [CrossRef] 
39. Chen, S.; Chen, X.; Wan, D.; Yi, X.; Sun, X.; Ji, L.; Wang, G. A lattice Boltzmann study of the collisions in a particle-bubble system under turbulent flows. Powder Technol. 2020, 361, 759-768. [CrossRef]

40. Wan, D.; Yi, X.; Wang, L.-P.; Sun, X.; Chen, S.; Wang, G. Study of collisions between particles and unloaded bubbles with point-particle model embedded in the direct numerical simulation of turbulent flows. Miner. Eng. 2020, 146, 106137. [CrossRef]

41. Chen, S.; Chen, X.; Wan, D.; Sun, X.; Ji, L.; Wu, K.; Yang, F.; Wang, G. Particle-resolved direct numerical simulation of collisions of bidisperse inertial particles in a homogeneous isotropic turbulence. Powder Technol. 2020, 376, 72-79. [CrossRef]

42. Wang, G.; Wan, D.; Peng, C.; Liu, K.; Wang, L.-P. LBM study of aggregation of monosized spherical particles in homogeneous isotropic turbulence. Chem. Eng. Sci. 2019, 201, 201-211. [CrossRef]

43. Yoon, R.-H.; Yordan, J.L. Induction time measurements for the quartz-Amine flotation system. J. Colloid Interface Sci. 1991, 141, 374-383. [CrossRef]

44. Xing, Y.; Gui, X.; Pan, L.; Pinchasik, B.-E.; Cao, Y.; Liu, J.; Kappl, M.; Butt, H.-J. Recent experimental advances for understanding bubble-particle attachment in flotation. Adv. Colloid Interface Sci. 2017, 246, 105-132. [CrossRef] [PubMed]

45. Christenson, H.K.; Claesson, P.M. Direct measurements of the force between hydrophobic surfaces in water. Adv. Colloid Interface Sci. 2001, 91, 391-436. [CrossRef]

46. Gomez-Flores, A.; Solongo, S.K.; Heyes, G.W.; Ilyas, S.; Kim, H. Bubble-particle interactions with hydrodynamics, XDLVO theory, and surface roughness for flotation in an agitated tank using CFD simulations. Miner. Eng. 2020, 152, 106368. [CrossRef]

47. Valderrama, L.; Rubio, J. High intensity conditioning and the carrier flotation of gold fine particles. Int. J. Miner. Process. 1998, 52, 273-285. [CrossRef]

48. Feng, B.; Lu, Y.; Feng, Q.; Ding, P.; Luo, N. Mechanisms of surface charge development of serpentine mineral. Trans. Nonferrous Met. Soc. China 2013, 23, 1123-1128. [CrossRef]

49. Yu, Y.; Cheng, G.; Ma, L.; Huang, G.; Wu, L.; Xu, H. Effect of agitation on the interaction of coal and kaolinite in flotation. Powder Technol. 2017, 313, 122-128. [CrossRef]

50. Wang, H.; Yang, W.; Li, D.; Zhang, C.; Yan, X.; Wang, L.; Zhang, H. Enhancement of coal flotation using impact flow conditioning pulp. J. Clean. Prod. 2020, 267, 122124. [CrossRef]

51. Zhang, X.; Manica, R.; Tchoukov, P.; Liu, Q.; Xu, Z. Effect of approach velocity on thin liquid film drainage between an air bubble and a flat solid surface. J. Phys. Chem. C 2017, 121, 5573-5584. [CrossRef]

52. Schulze, H. Hydrodynamics of bubble-mineral particle collisions. Miner. Procesing Extr. Metall. Rev. 1989, 5, 43-76. [CrossRef]

53. Schulze, H.J. New theoretical and experimental investigations on stability of bubble/particle aggregates in flotation: A theory on the upper particle size of floatability. Int. J. Miner. Process. 1977, 4, 241-259. [CrossRef]

54. Mao, L.; Yoon, R.-H. Predicting flotation rates using a rate equation derived from first principles. Int. J. Miner. Process. 1997, 51, 171-181. [CrossRef]

55. Wang, G.; Zhou, S.; Joshi, J.B.; Jameson, G.J.; Evans, G.M. An energy model on particle detachment in the turbulent field. Miner. Eng. 2014, 69, 165-169. [CrossRef]

56. Schulze, H.J. Flotation as heterocoagulation process: Possibilities of calculating the probability of flotation. In Coagulation and Flocculation; Dekker: New York, NY, USA, 1993.

57. Hui, S. Three-Phase Mixing and Flotation in Mechanical Cells. Ph.D. Thesis, University of Newcastle, Callaghan, Australia, 2001.

58. Nguyen, A.V.; Schulze, H.J. Colloidal Science of Flotation; Marcel Dekker: New York, NY, USA, 2004.

59. Jameson, G.J. Method and Apparatus for Flotation in a Fluidized Bed. PCT Patent Application No. WO 2008/104022, 4 September 2008.

60. Yoon, R.-H.; Mao, L. Application of Extended DLVO Theory, IV: Derivation of Flotation Rate Equation from First Principles. J. Colloid Interface Sci. 1996, 181, 613-626. [CrossRef]

61. Sherrell, I.M. Development of a Flotation Rate Equation from First Principles under Turbulent Flow Conditions. Ph.D. Thesis, Virginia Polytechnic Institute and State University, Blacksburg, VA, USA, 2004.

62. Do, H. Development of a Turbulent Flotation Model from First Principles. Ph.D. Thesis, Virginia Polytechnic Institute and State University, Blacksburg, VA, USA, 2010.

63. Wang, G.; Sathe, M.; Mitra, S.; Joshi, J.; Jameson, G.J.; Evans, G.M. Influence of grid-generated turbulence on detachment of a bubble anchored to a vertical cylindrical surface: Application to mineral flotation Systems. In Chemeca 2013: Challenging Tomorrow; Engineers Australia: Barton, Australia, 2013.

64. Zhang, M.; Wang, G.; Evans, G.M. Flow visualizations around a bubble detaching from a particle in turbulent flows. Miner. Eng. 2016, 92, 176-188. [CrossRef]

65. Wang, G.; Gao, Y.; Mitra, S.; Li, Y.; Zhou, S.; Evans, G. Instantaneous bond number for a particle detaching from a bubble. Int. J. Miner. Process. 2015, 142, 22-29. [CrossRef]

66. Wang, G.; Feng, D.; Nguyen, A.; Evans, G.M. The dynamic contact angle of a bubble with an immersed-in-water particle and its implications for bubble-particle detachment. Int. J. Miner. Process. 2016, 151, 22-32. [CrossRef]

67. Wang, G.; Evans, G.M.; Jameson, G.J. Bubble-particle detachment in a turbulent vortex II—Computational methods. Miner. Eng. 2017, 102, 58-67. [CrossRef]

68. Schulze, H.J. Physicochemical elementary processes in flotation. In Developments in Mineral Processing; Elsevier Science Publishers: Amsterdam, The Netherlands, 1983; p. 348. 
69. Wang, G.; Evans, G.M.; Jameson, G.J. Experiments on the detachment of particles from bubbles in a turbulent vortex. Powder Technol. 2016, 302, 196-206. [CrossRef]

70. Wang, G.; Evans, G.M.; Jameson, G.J. Bubble-particle detachment in a turbulent vortex I: Experimental. Miner. Eng. 2016, 92, 196-207. [CrossRef]

71. Jameson, G.J. New directions in flotation machine design. Miner. Eng. 2010, 23, 835-841. [CrossRef]

72. Wang, L.; Wang, Y.; Yan, X.; Wang, A.; Cao, Y. A numerical study on efficient recovery of fine-grained minerals with vortex generators in pipe flow unit of a cyclonic-static micro bubble flotation column. Chem. Eng. Sci. 2017, 158, 304-313. [CrossRef]

73. Zheng, K.; Yan, X.; Wang, L.; Zhang, H.; Cao, Y.; Guo, C. Turbulent effects of vortex generators on the separation of fine particles. Chem. Eng. J. 2021, 418, 129373. [CrossRef]

74. Yan, X.; Chen, Z.; Wang, L. Computational fluid dynamics (CFD) numerical simulation and particle image velocimetry (PIV) measurement of a packed flotation column. Physicochem. Probl. Miner. Process. 2018, 54, 395-405.

75. Zhang, M.; Li, T.; Ma, S.; Wang, G. An experimental study of copper sulfide flotation in a packed cyclonic-static microbubble flotation column. Sep. Sci. Technol. 2018, 53, 2238-2248. [CrossRef]

76. Zhang, M.; Li, T.; Wang, G. A CFD study of the flow characteristics in a packed flotation column: Implications for flotation recovery improvement. Int. J. Miner. Process. 2017, 159, 60-68. [CrossRef]

77. Gui, X.; Liu, J.; Cao, Y.; Cheng, G.; Li, S.; Wu, L. Flotation process design based on energy input and distribution. Fuel Process. Technol. 2014, 120, 61-70. [CrossRef]

78. Tabosa, E.; Runge, K.; Holtham, P.; Duffy, K. Improving flotation energy efficiency by optimizing cell hydrodynamics. Miner. Eng. 2016, 96-97 (Suppl. C), 194-202. [CrossRef]

79. Meng, J.; Tabosa, E.; Xie, W.; Runge, K.; Bradshaw, D.; Manlapig, E. A review of turbulence measurement techniques for flotation. Miner. Eng. 2016, 95, 79-95. [CrossRef]

80. Wang, G.; Yang, F.; Wu, K.; Ma, Y.; Peng, C.; Liu, T.; Wang, L.-P. Estimation of the dissipation rate of turbulent kinetic energy: A review. Chem. Eng. Sci. 2021, 229, 116133. [CrossRef]

81. Li, Q.; Peng, Z.; Liu, L.; Chen, S.; Liu, J.; Wang, L.-P.; Liu, T.; Wang, G. A comparison of different methods for estimating turbulent dissipation rate in under-resolved flow fields from synthetic PIV images. Chem. Eng. Res. Des. 2021, 175, 161-170. [CrossRef]

82. Safari, M.; Harris, M.; Deglon, D. The effect of energy input on the flotation of a platinum ore in a pilot-scale oscillating grid flotation cell. Miner. Eng. 2017, 110 (Suppl. C), 69-74. [CrossRef]

83. Safari, M.; Harris, M.; Deglon, D. The effect of energy input on the flotation kinetics of galena in an oscillating grid flotation cell. In Proceedings of the IMPC 2014-27th International Mineral Processing Congress (IMPC 2014), Santiago, Chile, 20-24 October 2014.

84. Massey, W.T.; Harris, M.C.; Deglon, D.A. The effect of energy input on the flotation of quartz in an oscillating grid flotation cell. Miner. Eng. 2012, 36-38, 145-151. [CrossRef]

85. Changunda, K.; Harris, M.; Deglon, D.A. Investigating the effect of energy input on flotation kinetics in an oscillating grid flotation cell. Miner. Eng. 2008, 21, 924-929. [CrossRef]

86. Wang, G.C.; Ge, L.H.; Mitra, S.; Evans, G.M.; Joshi, J.B.; Chen, S.Y. A review of CFD modelling studies on the flotation process. Miner. Eng. 2018, 127, 153-177. [CrossRef]

87. Koh, P.T.L.; Schwarz, M.P. CFD modelling of bubble-particle attachments in flotation cells. Miner. Eng. 2006, 19, 619-626. [CrossRef]

88. Pereira, L.; Frenzel, M.; Hoang, D.H.; Tolosana-Delgado, R.; Rudolph, M.; Gutzmer, J. Computing single-particle flotation kinetics using automated mineralogy data and machine learning. Miner. Eng. 2021, 170, 107054. [CrossRef]

89. Pereira, L.; Frenzel, M.; Khodadadzadeh, M.; Tolosana-Delgado, R.; Gutzmer, J. A self-adaptive particle-tracking method for minerals processing. J. Clean. Prod. 2021, 279, 123711. [CrossRef] 